\title{
Comparison of Two pMDIs in Adult Asthmatics: A Randomized Double-Blind Double-Dummy Clinical Trial
}

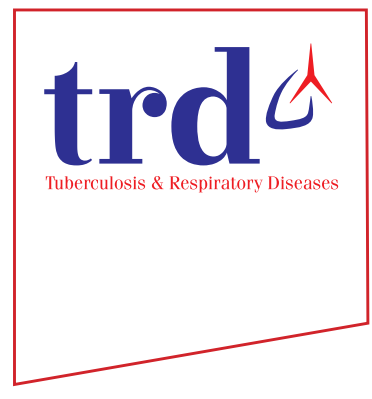

\author{
Tae-Hyun Nam, M.D. ${ }^{1 *(\mathbb{D}}$, Sung-Yoon Kang, M.D., Ph.D. ${ }^{1, *(\mathbb{1})}$, Sang Min Lee, M.D., Ph.D. ${ }^{1}{ }^{\mathbb{D}}$, Tae- \\ Bum Kim, M.D., Ph.D. ${ }^{\circledR}$ and Sang Pyo Lee, M.D., Ph.D. ${ }^{1}$ \\ ${ }^{1}$ Division of Pulmonology and Allergy, Department of Internal Medicine, Gachon University Gil Medical Center, Incheon, \\ ${ }^{2}$ Department of Allergy and Clinical Immunology, Asan Medical Center, University of Ulsan College of Medicine, Seoul, \\ Republic of Korea
}

Background: Only a few studies directly compared the therapeutic efficacy and safety of two pressurized metereddose inhalers (pMDIs) in asthma. We analyzed the asthma treatment outcomes, safety, and patient preferences using formoterol/beclomethasone (FORM/BDP), a pMDI with extra-fine particles, compared with formoterol/budesonide (FORM/BUD), another pMDI with non-extra-fine particles.

Methods: In this randomized, double-blind, double-dummy parallel group study, 40 adult asthmatics were randomized to FORM/BDP group ( $\mathrm{n}=18$; active FORM/BDP and placebo FORM/BUD) or FORM/BUD group ( $\mathrm{n}=22$; active FORM/BUD and placebo FORM/BDP). During the two visits (baseline and end of 8-week treatment), subjects were asked to answer questionnaires including asthma control test (ACT), asthma control questionnaires (ACQ), and Quality of Life Questionnaire for Adult Korean Asthmatics (QLQAKA). Lung function, compliance with inhaler, and inhaler-handling skills were also assessed. Results: Ten subjects in the FORM/BDP group and 14 in the FORM/BUD group completed follow-up visits. ACT, ACQ, QLQAKA (a primary outcome), and adverse events did not differ between two groups. We found that the increase in forced expiratory volume in 1 second/forced vital capacity and forced expiratory flow at $25 \%$ to $75 \%$ of the pulmonary volume in the FORM/BDP group was higher than in the FORM/BUD group. Regarding preference, subjects responded that the flume velocity of FORM/BDP was higher, but more adequate than that of FORM/BUD. They also answered that FORM/BDP reached the trachea and bronchus and irritated them significantly more than FORM/BUD.

Conclusion: The use of pMDI with extra-fine particles may relieve small airway obstruction more than the one with non-extra-fine particles despite no significant differences in overall treatment outcomes. Some asthmatics have a misconception about the adequacy of high flume velocity of pMDIs.

Keywords: Asthma; Metered-Dose Inhalers; Particle Size; Treatment Outcome; Preference

Address for correspondence: Sang Min Lee, M.D., Ph.D.

Department of Internal Medicine, Gachon University Gil Medical Center, 21 Namdong-daero 774beon-gil, Namdong-gu, Incheon 21565, Republic of Korea

Phone: 82-32-458-2713, Fax: 82-32-469-4320, E-mail: sangminlee77@naver.com

Address for correspondence: Tae-Bum Kim, M.D., Ph.D.

Department of Allergy and Clinical Immunology, Asan Medical Center, University of Ulsan College of Medicine, 88 Olympic-ro 43-gil, Songpa-gu, Seoul 05505, Republic of Korea

Phone: 82-2-3010-3287, Fax: 82-2-3010-6969, E-mail: tbkim@amc.seoul.kr

*Tae-Hyun Nam and Sung-Yoon Kang contributed equally to this article.

Received: Aug. 12, 2021, Revised: Oct. 26, 2021, Accepted: Nov. 24, 2021, Published online: Nov. 29, 2021

(c) It is identical to the Creative Commons Attribution Non-Commercial License (http://creativecommons.org/licenses/by-nc/4.0/) 


\section{Introduction}

Asthma, which has a prevalence of $3.6 \%$ worldwide, is the chronic respiratory disease with the second highest mortality rate $^{1}$. Regular administration of inhaled corticosteroids (ICS) with or without long-acting beta2 agonists (LABAs) using inhaler devices is the most recommended treatment option for asthma worldwide ${ }^{2}$. Inhaler therapy for asthma can maximize antiinflammatory and bronchodilatory effects and minimize the potential side effects, including systemic immunosuppression and interruption of the hypothalamic-pituitary-adrenal axis ${ }^{3}$.

Portable inhaler devices for treatment mainly consist of dry powdered inhalers (DPIs) and pressurized metered-dose inhalers (pMDIs) ${ }^{4}$. Various DPIs have been developed to treat asthma and evaluated for their therapeutic efficacy, patient preferences, and patient skills in handling the inhalers during their development and after sales ${ }^{5-8}$. In contrast, few studies have explored pMDIs. Most of the studies compared pMDIs propelled by hydrofluoroalkane (HFA) and chlorofluorocarbon (CFC) in the 2000s, when HFA was substituted for CFC to avoid ozone depletion ${ }^{9-11}$.

Meanwhile, inhaled drugs with extra-fine particles are more effectively distributed in the peripheral airway, which may lead to potentially greater therapeutic effects since inflammation and remodeling occur in the entire airway including peripheral bronchioles of asthma patients ${ }^{12-14}$. Inhaled drugs with extra-fine particles may guarantee better asthma treatment outcomes, reducing asthma exacerbation (AE) than other ICS/LABAs with non-extra-fine particles in asthma ${ }^{15-17}$. However, there was no study which performed a direct headto-head comparison of treatment outcomes between inhaled drugs with extra-fine particles and those with non-extra-fine particles under other controlled clinical conditions (including inhaler device).

Here we report a phase IV double-blind, double-dummy randomized clinical trial that compared asthma treatment outcomes using two pMDIs containing formoterol fumarate dihydrate/beclomethasone dipropionate (FORM/BDP), an ICS/LABA with extra-fine particles and formoterol fumarate dihydrate/budesonide (FORM/BUD), an ICS/LABA with non- extra-fine particles based on patient responses to relevant questionnaires including asthma control test (ACT), asthma control questionnaires (ACQ), and Quality of Life Questionnaire for Adult Korean Asthmatics (QLQAKA). Safety, patient preferences, and skills in handling inhalers were also assessed between two pMDIs. Our primary objective was analyzing the asthma treatment outcomes, safety, and patient preferences using an ICS/LABA with extra-fine particles compared with those containing non-extra-fine particles. Towards this end, the ideal strategy is to use the same pMDI device containing the same ICS/LABA with different particulate properties (one with extra-fine particles and another with non-extra-fine particles). However, we could not control the device or the ICS/ LABA (especially ICS), because this study was an investigatorinitiated trial comparing commercially available pMDIs containing ICS/LABA for asthma treatment. In this study, FORM/BUD was selected as a comparator with non-extra-fine particles, because it contains budesonide with similar daily equivalent dose as well as the same LABA of formoterol fumarate dihydrate ${ }^{2}$.

\section{Materials and Methods}

\section{Study design}

This was a phase IV randomized, double-blind, doubledummy parallel trial performed at a single study center in Incheon, Republic of Korea (Figure 1). After obtaining informed consent, unblinded staff randomly enrolled subjects (1:1) into either of the two groups using an Excel program (Microsoft, Redmond, WA, USA) with a block size of 10. The groups were: (1) one puff of active FORM/BDP (Foster [formoterol fumarate dihydrate $6 \mu \mathrm{g} /$ beclomethasone dipropionate $100 \mu \mathrm{g}$ ], Chiesi Pharmaceuticals, Parma, Italy) and one puff of placebo FORM/BUD twice daily for 8 weeks (FORM/ BDP group); and (2) one puff of active FORM/BUD (Symbicort Rapihaler [formoterol fumarate dihydrate $4.5 \mu \mathrm{g} /$ budesonide $160 \mu \mathrm{g}]$, AstraZeneca, London, UK) and one puff of placebo FORM/BDP administered twice daily for 8 weeks (FORM/

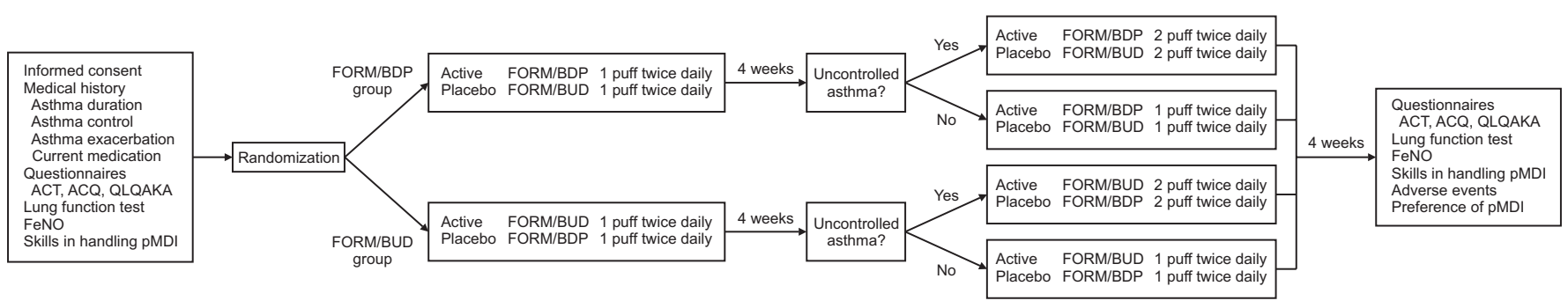

Figure 1. Schematic representation of the study design. FORM: formoterol fumarate dihydrate; BDP: beclomethasone dipropionate; ACQ: Asthma Control Questionnaire; ACT: Asthma Control Test; BUD: budesonide; QLQAKA: Quality of Life Questionnaire for Adult Korean Asthmatics; FeNO: fractional nitric oxide concentration in exhaled breath; pMDI: pressurized metered-dose inhaler. 
BUD group). Four weeks after randomization, investigators called subjects by phone at a predetermined time and assessed asthma control and AE. Subjects were asked to increase the dose of each inhaler (one active and the other placebo) from one puff twice daily to two puffs twice daily if the following conditions were satisfied, which indicated uncontrolled asthma: (1) daytime symptoms $\geq 3 / \mathrm{wk}$, (2) reliever uses $\geq 3 / \mathrm{wk}$, (3) nocturnal symptoms, and (4) limitation of activity due to asthma. AE was indicated if persistent asthma symptoms required admission to the general ward or intensive care unit, visiting the emergency room, unscheduled visits to the outpatient clinic, or use of oral corticosteroids.

Participants and investigators assessing treatment outcomes and adverse events were blinded to the treatment; blinding was maintained until all assessments and recordings were completed.

\section{Study population}

Subjects enrolled in the study were adult asthmatics using low-dose ICS/LABA. The inclusion criteria were: (1) age $\geq 19$ years; (2) typical asthma symptoms of dyspnea and wheezing aggravated by exercise, a cold, climate or diurnal change in temperature, and exposure to allergens, air pollution, tobacco smoke, or foul odor; (3) bronchodilator or treatment response proven by repetitive lung function tests (an increase in forced expiratory volume in 1 second $\left[\mathrm{FEV}_{1}\right]$ of $200 \mathrm{~mL}$ and $12 \%$ from baseline after the inhalation of salbutamol or appropriate asthma treatment) or airway hyperresponsiveness (AHR) verified by methacholine challenge test (provocative concentration of methacholine causing a $20 \%$ drop in $\mathrm{FEV}_{1}\left[\mathrm{PC}_{20}\right] \leq 16 \mathrm{mg} / \mathrm{mL}$ ); (4) inhalation of low-dose ICS and LABA for asthma treatment ${ }^{2}$. The exclusion criteria were: (1) malignancy or other serious comorbid diseases that could influence the study; (2) previous use of FORM/BDP or FORM/BUD; (3) pregnancy or lactation; (4) inadequate ICS/LABA, such as poor compliance to the inhaled medication or side effects of ICS or LABAs; (5) lack of patient consent to participate in the study.

\section{Asthma treatment outcomes}

Baseline parameters of patient's medical history, including symptom duration, time of asthma diagnosis and treatment, comorbid allergic diseases, asthma control, $\mathrm{AE}$, and current medications, were recorded. Subjects were also asked to respond to questionnaires including ACT, ACQ, and QLQAKA, and to undergo lung function tests and measurement of fractional exhaled nitric oxide $(\mathrm{FeNO})^{18-20}$. These parameters were measured again at the end of the 8-week study drug treatment. Local or systemic adverse events were also recorded at the end of the 8-week treatment with the study drug.

\section{Skills in handling and compliance with pMDIs}

Before the start of the study drug treatment, subject skills in handling pMDIs were evaluated as reported previously, and any errors were corrected immediately after evaluation. These skills were evaluated again after the 8-week study treatment ${ }^{21}$. Since active and placebo FORM/BDP used in this study did not have dose counters, the remnant doses of active and placebo FORM/BUD, which had dose counters, were recorded to determine compliance with study drugs in the FORM/BUD and FORM/BDP groups, respectively.

\section{Preference for pMDIs}

At the end of the 8-week study, subjects were asked to respond to inhaler preference questionnaires, as described in previous reports ${ }^{5,6,8,11,22}$. The subjects were asked about design, the connection between the cap and the body, size, grip, ease of pressing, general ease and convenience, flume velocity, irritation, taste, smell, feeling of the drug reaching the trachea

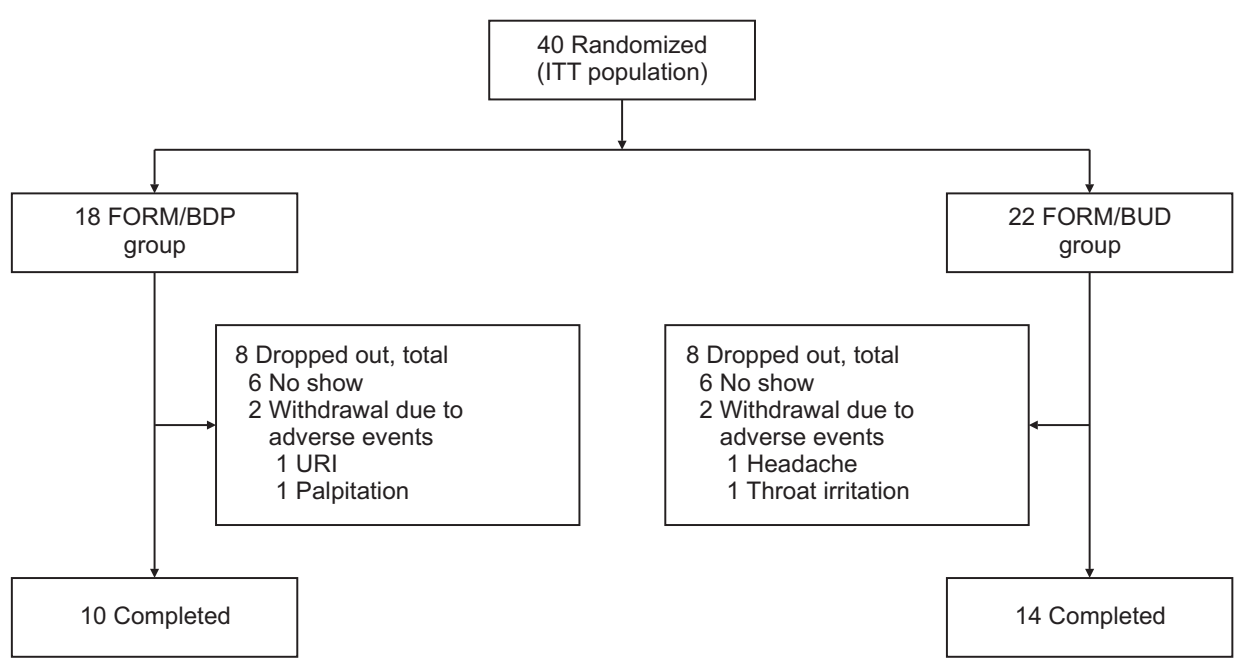

Figure 2. Participant flowchart. FORM: formoterol fumarate dihydrate; BDP: beclomethasone dipropionate; BUD: budesonide; FORM: formoterol fumarate dihydrate; ITT: intention to treat; URI: upper respiratory tract infection. 


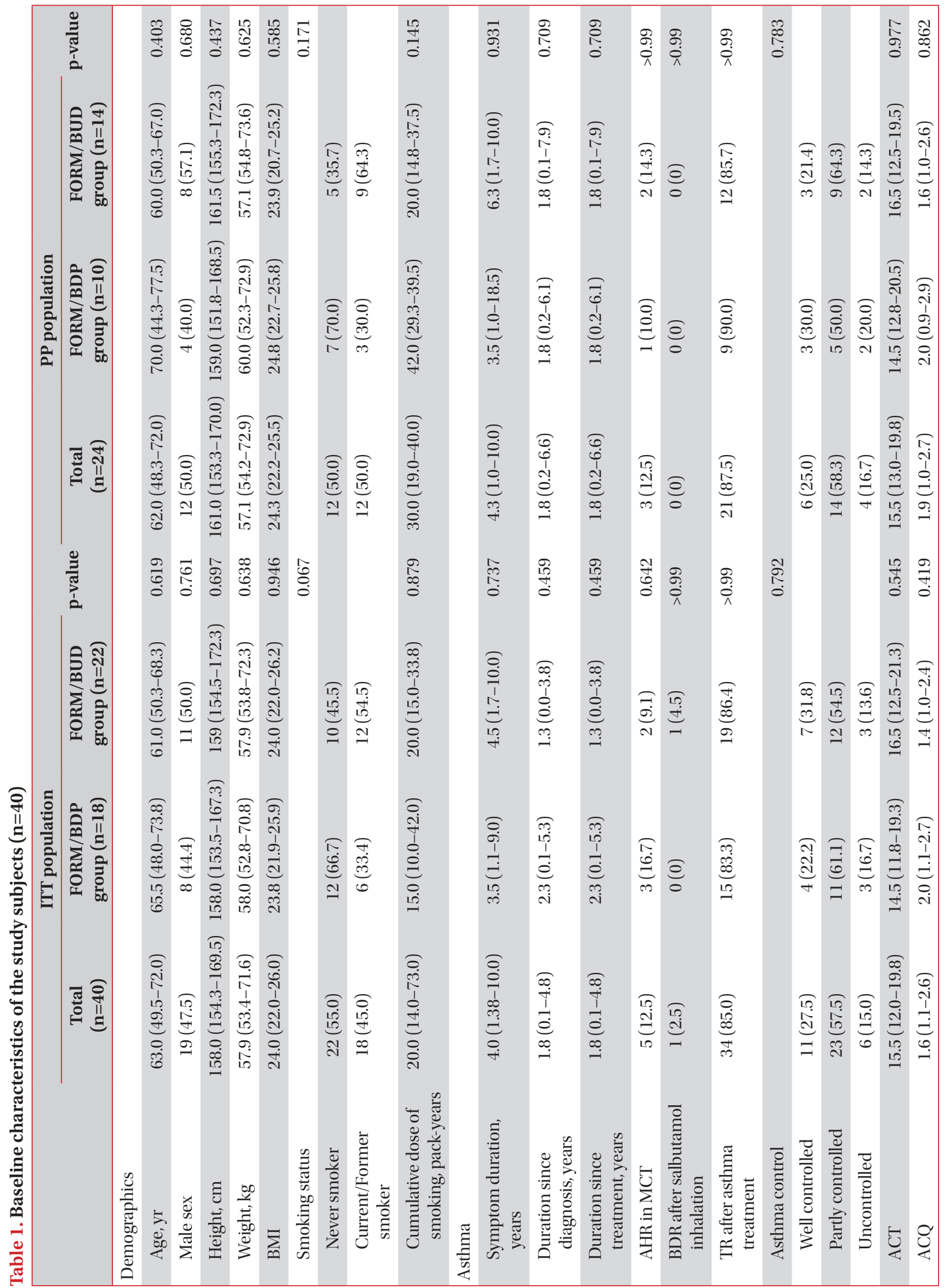




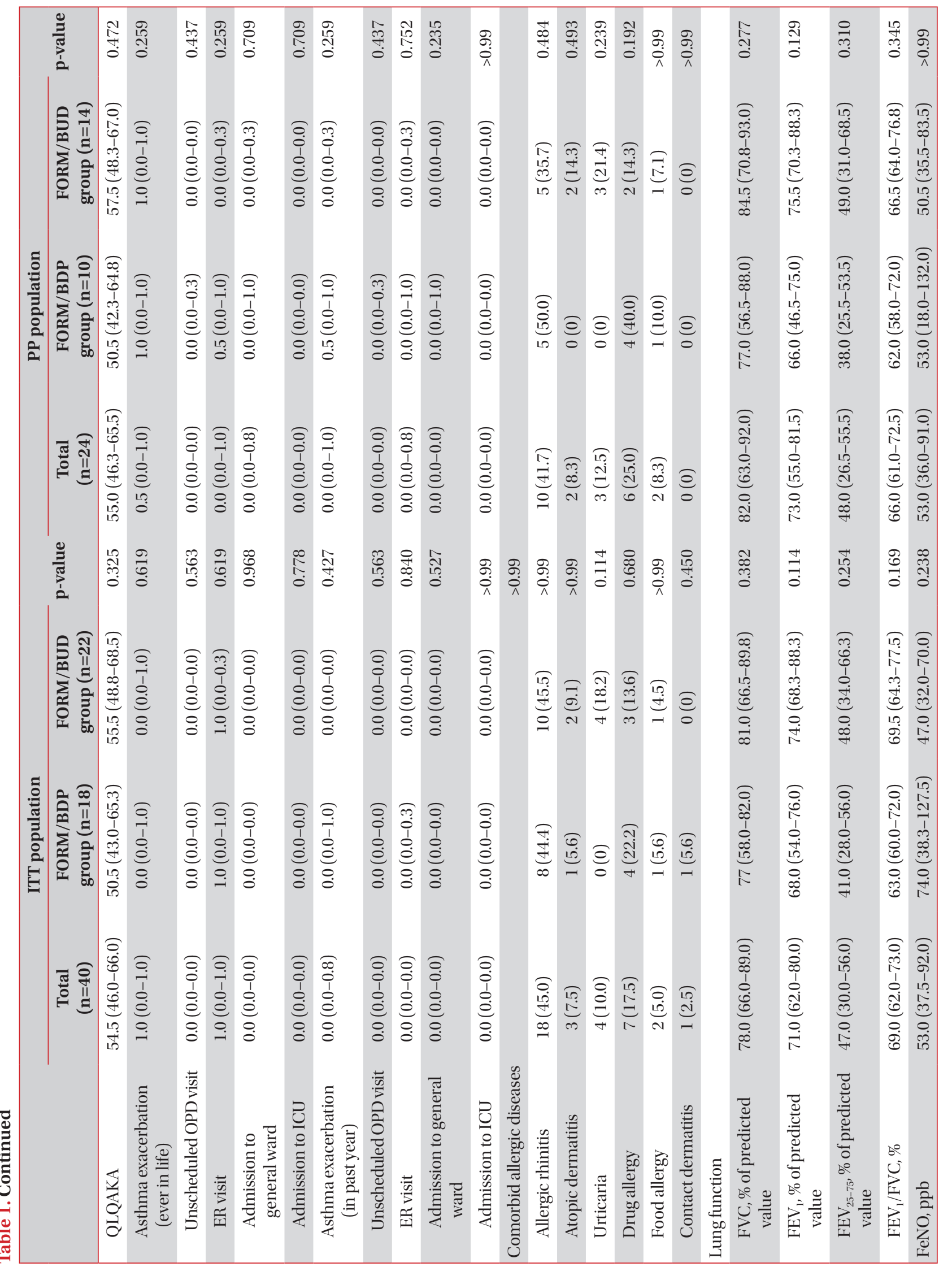




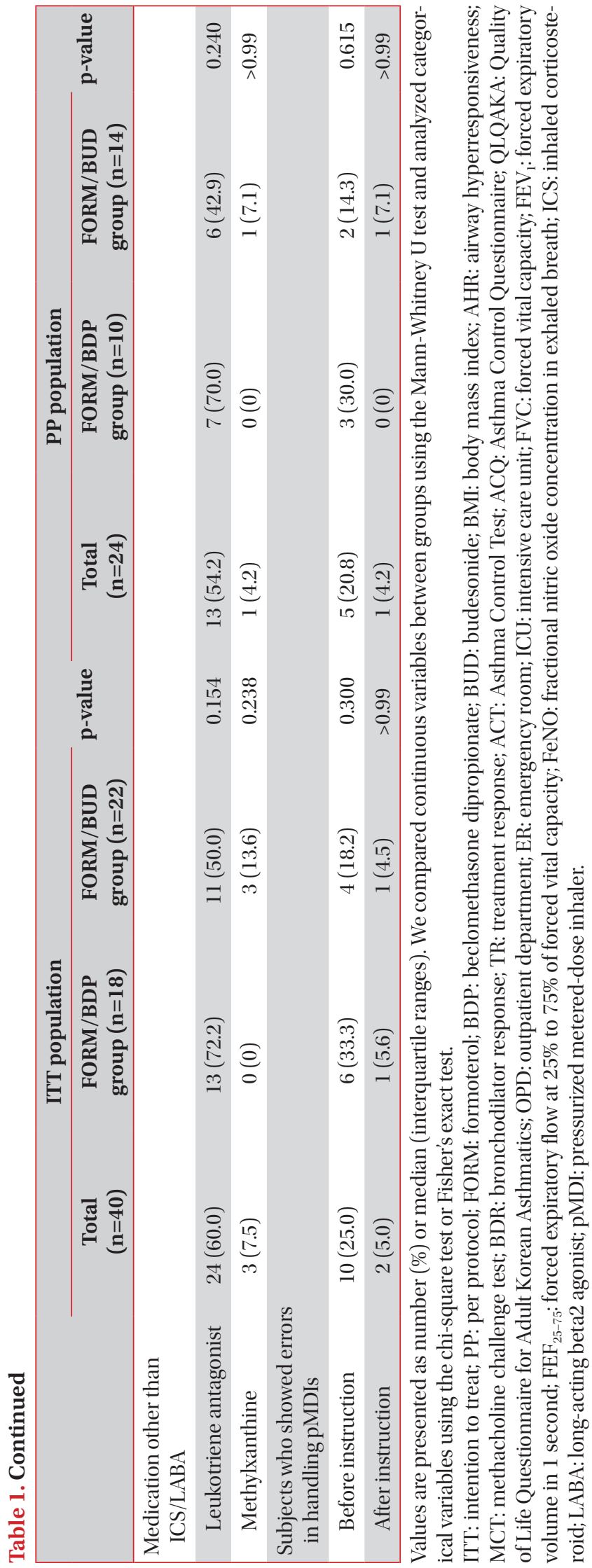

and bronchus, overall satisfaction, and willingness to obtain a prescription for an inhaler. At the end of the study, subjects were asked to select one of the two pMDIs or other inhalers.

\section{Statistical analyses}

We compared continuous variables between groups using the Mann-Whitney U test and analyzed categorical variables using the chi-square test or Fisher's exact test. Data are shown as medians (interquartile ranges [IQRs]) for continuous variables and frequencies (\%) for categorical variables. An adjusted $\mathrm{p}<0.05$ was considered statistically significant. All statistical analyses were performed with SPSS version 19 (IBM Corp., Armonk, NY, USA).

\section{Sample size}

A power calculation was performed with a two-sample t test for the primary outcome variable of QLQAKA. We expected a difference of 10.0 in the QLQAKA scores between the two groups 8 weeks after treatment. We estimated that the SD would be 10.0. Aiming for a power of 0.80 and using a type I error rate of 0.05 and $40 \%$ loss to follow-up, we calculated the sample size at 40.

\section{Ethical considerations}

The study protocol was reviewed and approved by the affiliated institutional review board (IRB approval number: GFIRB2018-232). The study was registered at Clinical Research Information Service, Republic of Korea (CRIS KCT0003538). All subjects were enrolled after informed consent obtained.

\section{Results}

\section{Participant flowchart}

Patients were screened between August 2018 and February 2019. We assessed 45 subjects for eligibility; three subjects were not eligible, and two declined to participate after being introduced to the study. The remaining 40 subjects were randomly allocated into the FORM/BDP group $(\mathrm{n}=18)$ or the FORM/BUD group ( $\mathrm{n}=22)$ (Figure 2). Of the 40 participants, $24(60.0 \%)$ completed the 8-week treatment period; $12(30.0 \%)$ dropped out for not showing up on the day of the follow-up visit, and four (10.0\%) withdrew because of adverse events. A total of 10 patients in the FORM/BDP group and 14 in the FORM/BUD group completed the study. Asthma treatment outcomes, lung function, adverse events, compliance with inhalers, subject preferences regarding inhalers, and skills in handling inhalers were analyzed. 


\section{Baseline characteristics}

Overall, baseline characteristics were balanced between the treatment groups (Table 1). Participants had a median age of 63.0 years (IQR, 49.5-72.0), and 47.5\% of participants were male. Median height, weight, and BMI were $158.0 \mathrm{~cm}$ (IQR, 154.3-169.5), $57.9 \mathrm{~kg}$ (IQR, 53.4-71.6), and 24.0 (IQR, $22.0-26.0)$, respectively. A total of $22(55.0 \%)$ and $18(45.0 \%)$ patients were never-smokers, and current/former smokers, respectively. Among smokers, the median cumulative dose of smoking was 20.0 pack-years (IQR, 14.0-73.0). The median asthma symptom duration was 4 years (IQR, 1.38-10.0), and the time since first diagnosis and treatment was 1.8 years (IQR, 0.1-4.8). Five subjects (12.5\%) showed AHR in the methacholine challenge test. One subject (1.5\%) and 34 others $(85.0 \%)$ showed bronchodilator response and treatment response, respectively, with an $\mathrm{FEV}_{1}$ increase of $200 \mathrm{~mL}$ and $12 \%$ from baseline after the inhalation of salbutamol or appro- priate asthma treatment. Asthma was well-controlled, partlycontrolled, and uncontrolled in 11 (27.5\%), 23 (57.5\%), and six (15.0\%), respectively, according to the Global Initiative for Asthma (GINA) criteria. Median ACT, ACQ, and QLQAKA scores were 15.5 (IQR, 12.0-19.8), 1.6 (IQR, 1.1-2.6), and 54.5 (IQR, 46.0-66.0), respectively. Median frequencies of AE ever in life and in the past year were 1.0 (IQR, 0.0-1.0) and 0.0 (IQR, $0.0-0.8)$, respectively. In terms of comorbid allergic diseases, $18(45.0 \%)$, three $(7.5 \%)$, four $(10.0 \%)$, seven $(17.5 \%)$, two (5.0\%), and one (2.5\%) had allergic rhinitis, atopic dermatitis, urticaria, drug allergy, food allergy, and contact dermatitis, respectively. The baseline median percent-predicted forced vital capacity (FVC), $\mathrm{FEV}_{1}$, and forced expiratory flow at 25\% to $75 \%$ of forced vital capacity $\left(\mathrm{FEF}_{25-75}\right)$ values were 78.0 (IQR, 66.0-89.0), 71.0\% (IQR, 62.0\%-80.0\%), and 47.0\% (IQR, $30.0 \%-56.0 \%$ ), respectively. Baseline $\mathrm{FEV}_{1} / \mathrm{FVC}$ and FeNO values were $69.0 \%$ (IQR, 62.0\%-73.0\%) and $53.0 \mathrm{ppb}$ (IQR, 37.5-92.0), respectively. Leukotriene antagonist and methyl-

Table 2. Asthma treatment outcomes in PP population $(\mathbf{n}=24)$

\begin{tabular}{|c|c|c|c|c|}
\hline & $\begin{array}{c}\text { Total } \\
(n=24)\end{array}$ & $\begin{array}{l}\text { FORM/BDP } \\
\operatorname{group}(n=10)\end{array}$ & $\begin{array}{l}\text { FORM/BUD } \\
\text { group }(n=14)\end{array}$ & p-value \\
\hline Asthma control (after 4-week treatment) & & & & 0.664 \\
\hline Well controlled & $17(70.8)$ & $7(70.0)$ & $10(71.4)$ & \\
\hline Partly controlled & $3(12.5)$ & $1(10.0)$ & $2(15.4)$ & \\
\hline Uncontrolled & $4(16.7)$ & $2(20.0)$ & $2(15.4)$ & \\
\hline Asthma control (after 8-week treatment) & & & & 0.556 \\
\hline Well controlled & $15(62.5)$ & $5(50.0)$ & $10(71.4)$ & \\
\hline Partly controlled & $7(29.2)$ & $4(40.0)$ & $3(21.4)$ & \\
\hline Uncontrolled & $2(8.3)$ & $1(10.0)$ & $1(7.1)$ & \\
\hline ACT change from baseline & $0.5(-2.0$ to 5.8$)$ & $-1.5(-2.5$ to 5.5$)$ & $1.5(-2.0$ to 6.0$)$ & 0.443 \\
\hline ACQ change from baseline & $0.0(-0.6$ to 0.5$)$ & $0.4(-0.6$ to 0.8$)$ & $-1.0(-4.5$ to 2.0$)$ & 0.095 \\
\hline QLQAKA change from baseline & $-15.5(-20.5$ to -7.5$)$ & $-14.0(-17.5$ to -5.5$)$ & $-17.0(-21.0$ to -6.0$)$ & 0.752 \\
\hline \multicolumn{5}{|l|}{ Lung function } \\
\hline FVC change, $\%$ of baseline & $1.5(-8.8$ to 12.1$)$ & $1.9(-11.6$ to 31.3$)$ & $0.9(-6.6$ to 7.0$)$ & 0.554 \\
\hline $\mathrm{FEV}_{1}$ change, $\%$ of baseline & $1.4(-7.0$ to 13.9$)$ & $1.8(-2.1$ to 55.6$)$ & $-2.2(-7.9$ to 11.5$)$ & 0.193 \\
\hline $\mathrm{FEF}_{25-75}$ change, $\%$ of baseline & $11.3(-10.3$ to 30.5$)$ & $17.9(3.5$ to 128.2$)$ & $2.9(-16.4$ to 17.9$)$ & $0.037^{*}$ \\
\hline $\mathrm{FEV}_{1} / \mathrm{FVC}$ change, $\%$ & $1.0(-1.0$ to 5.0$)$ & $3.0(1.0$ to 13.5$)$ & $1.0(-3.8$ to 3.8$)$ & $0.043^{*}$ \\
\hline FeNO change from baseline, ppb & $1.0(-34.0$ to 31.0$)$ & $1.0(-25.0$ to 5.0$)$ & $-1.5(-58.0$ to 37.8$)$ & $>0.99$ \\
\hline Compliance to inhaler, $\%$ & 80.4 (70.6 to 94.2$)$ & $78.4(68.4$ to 95.8$)$ & $84.0(68.8$ to 93.9$)$ & 0.841 \\
\hline Subjects who showed errors in handling pMDIs & $0(0)$ & $0(0)$ & $0(0)$ & $>0.99$ \\
\hline
\end{tabular}

Values are presented as number (\%) or median (interquartile range). We compared continuous variables between groups using the MannWhitney $U$ test and analyzed categorical variables using the chi-square test or Fisher's exact test.

${ }^{*} \mathrm{p}<0.05$, in comparing variables between the two groups.

PP: per protocol; FORM: formoterol fumarate dihydrate; BDP: beclomethasone dipropionate; BUD: budesonide; ACT: Asthma Control Test; ACQ: Asthma Control Questionnaire; QLQAKA: Quality of Life Questionnaire for Adult Korean Asthmatics; FVC: forced vital capacity; FEV forced expiratory volume in 1 second; $\mathrm{FEF}_{25-75}$ : forced expiratory flow at $25 \%$ to $75 \%$ of forced vital capacity; FeNO: fractional nitric oxide concentration in exhaled breath; pMDI: pressurized metered-dose inhaler. 
xanthine were prescribed as other asthma controllers in 24 $(60.0 \%)$ and three $(7.5 \%)$ subjects, respectively. Ten subjects (25.0\%) showed errors in handling pMDIs; however, only two (5.0\%) showed errors after instruction and immediate correction.

Among intention-to-treat and per protocol populations, no differences in baseline characteristics were found between the FORM/BDP and the FORM/BUD groups.

\section{Asthma treatment outcomes}

Asthma treatment outcomes are shown in Table 2. There were no differences in asthma control at 4 and 8 weeks or in asthma symptom scores, including ACT, ACQ, and QLQAKA scores, between the two groups 8 weeks after treatment. In four subjects (two in the FORM/BDP group and two in the FORM/BUD group) with uncontrolled asthma 4 weeks after treatment, the inhalation doses of both active and placebo drugs were escalated from 1 puff twice daily to 2 puffs twice daily. In two subjects (one in the FORM/BDP group and one in the FORM/BUD group), asthma remained uncontrolled 8 weeks after treatment. In terms of lung function, changes in FVC and $\mathrm{FEV}_{1}$ were not different between the two groups, whereas those in $\mathrm{FEF}_{25-75}$ and $\mathrm{FEV}_{1} / \mathrm{FVC}$ were significantly higher in the FORM/BDP group than in the FORM/BUD group 8 weeks after treatment ( $17.9 \%$ of baseline [IQR, 3.5128.2 ] vs. 2.9 [IQR, -16.4 to 17.9 ], $\mathrm{p}=0.037 ; 3.0 \%$ [IQR, 1.0-13.5] vs. 1.0 [IQR, -3.8 to 3.8], $\mathrm{p}=0.043$, respectively) (Figure 3). Changes in FeNO, compliance with inhalers, and skills in handling inhalers did not differ between the two groups.

A

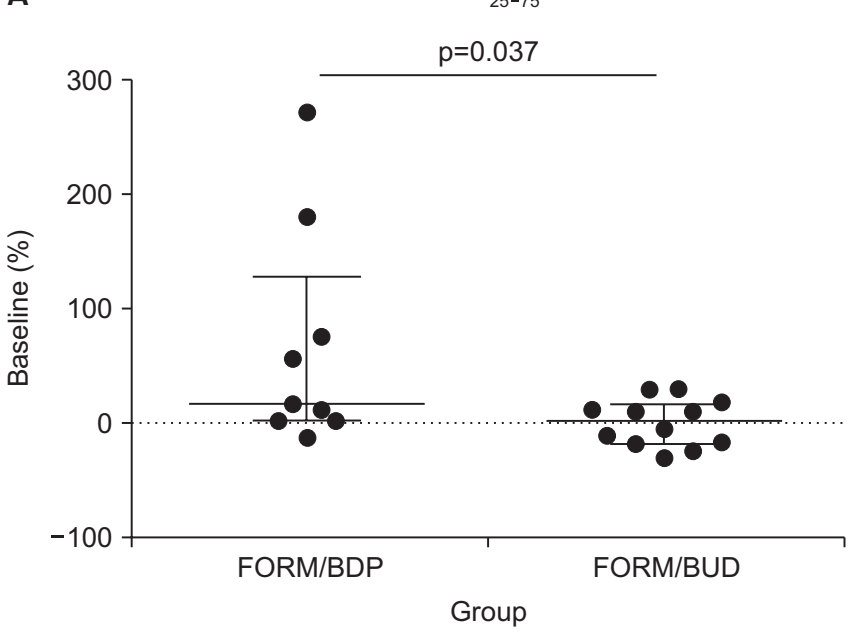

\section{Adverse events}

Adverse events during the study are presented in Supplementary Table S1. The most common adverse event was dry throat $(37.5 \%)$, followed by cough (25.0\%), voice difficulty (20.8\%), hoarseness (20.8\%), dyspnea (12.5\%), a feeling of humid throat (12.5\%), other abnormal feelings in the throat (8.3\%), chest discomfort (8.3\%), tremor (8.3\%), headache (8.3\%), and palpitations (4.2\%). These adverse events did not differ between the two groups.

\section{Preference and choice of pMDI}

Subjects' preference and their final choice of inhaler at the end of the study are shown in Table 3 and Supplementary Figure S1. There were no differences in preference between FORM/BDP and FORM/BUD in terms of design, the connection between the cap and body, size, grip, convenience, ease, and smell. Subjects responded that the taste of FORM/BDP was stronger than that of FORM/BUD (median, 5.0; IQR, 0.065.0 vs. median, $0.0 ; \mathrm{IQR}, 0.0-10.0 ; \mathrm{p}=0.030$ ); however, there were no differences in preference between the two pMDIs with regard to taste. Subjects responded that the flume velocity of FORM/BDP was higher (median, 80; IQR, 50.0-100.0 vs. median, 50.0; IQR, 32.5-50.0; $\mathrm{p}=0.011$ ), but more adequate (median, 92.5; IQR, 50.0-100.0 vs. median, 50; IQR, 32.5-77.5; $\mathrm{p}=0.013$ ) and that inhaled FORM/BDP reached the trachea and bronchus more than inhaled FORM/BUD (median, 87.5; IQR, 50.0-100.0 vs. median, 30.0; IQR, 0.0-50.0; $\mathrm{p}<0.001)$ and consequently was more irritating (median, 55; IQR, 50.0-100.0 vs. median, 12.5; IQR, $0.0-50.0 ; \mathrm{p}=0.001$ ). The overall satisfac-

B

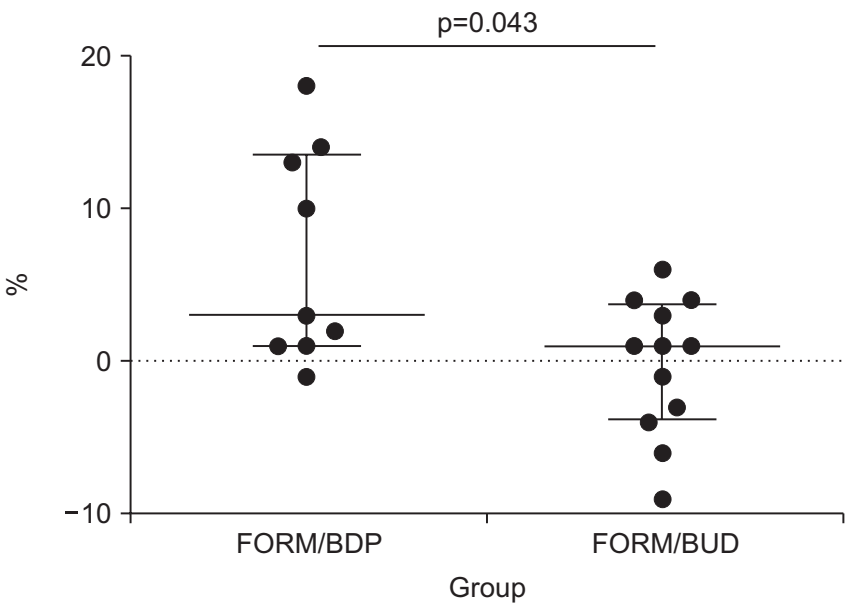

Figure 3. Change in lung function after 8-week treatment. (A) $\mathrm{FEF}_{25-75}$. (B) $\mathrm{FEV}_{1} / \mathrm{FVC}$. Bars indicate median with interquartile range. p<0.05 comparing variables between the FORM/BDP and FORM/BUD groups. FORM: formoterol fumarate dihydrate; BDP: beclomethasone dipropionate; BUD: budesonide; $\mathrm{FEF}_{25-75}$ : forced expiratory flow at $25 \%$ to $75 \%$ of forced vital capacity; $\mathrm{FEV}_{1}$ : forced expiratory volume in 1 second; FVC: forced vital capacity. 
Table 3. Patients' agreement (\%) with each description on two pMDIs in PP population (n=24)

\begin{tabular}{|c|c|c|c|}
\hline Description & FORM/BDP & FORM/BUD & p-value \\
\hline \multicolumn{4}{|l|}{ Design and size } \\
\hline I am satisfied with the design of inhaler & $60.0(50.0-100.0)$ & $50.0(50.0-80.0)$ & 0.068 \\
\hline I am satisfied with the connection (or disconnection) between cap and body & $55.0(50.0-100.0)$ & $50.0(50.0-87.5)$ & 0.244 \\
\hline The inhaler is large & $50.0(50.0-50.0)$ & $50.0(50.0-50.0)$ & 0.498 \\
\hline I am satisfied with the size of inhaler & $70.0(50.0-100.0)$ & $56.0(50.0-97.5)$ & 0.168 \\
\hline \multicolumn{4}{|l|}{ Convenience and easiness } \\
\hline It is convenient to grip the inhaler & $80.0(50.0-100.0)$ & $55.0(50.0-100.0)$ & 0.167 \\
\hline It is easy to press the canister of the inhaler & $65.0(50.0-100.0)$ & $70.0(50.0-100.0)$ & 0.883 \\
\hline It is generally easy to use the inhaler & $95.0(55.0-100.0)$ & $70.0(50.0-100.0)$ & 0.123 \\
\hline It is generally convenient to use the inhaler & $100.0(55.0-100.0)$ & $70.0(50.0-100.0)$ & 0.235 \\
\hline \multicolumn{4}{|l|}{ Smell and taste } \\
\hline The smell of the inhaled drug is strong & $20.0(0.0-67.5)$ & $0.0(0.0-42.5)$ & 0.061 \\
\hline I am satisfied with the smell of the inhaled drug & $0.0(0.0-50.0)$ & $0.0(0.0-50.0)$ & 0.336 \\
\hline The taste of the inhaled drug is strong & $5.0(0.0-65.0)$ & $0.0(0.0-10.0)$ & $0.030^{*}$ \\
\hline I am satisfied with the taste of the inhaled drugs & $0.0(0.0-50.0)$ & $0.0(0.0-50.0)$ & 0.786 \\
\hline \multicolumn{4}{|l|}{ Flume and inhaled drug } \\
\hline The velocity of the flume is high & $80.0(50.0-100.0)$ & $50.0(32.5-50.0)$ & $0.011^{*}$ \\
\hline The velocity of the flume is adequate & $92.5(50.0-100.0)$ & $50.0(32.5-77.5)$ & $0.013^{*}$ \\
\hline I feel the inhaled drug reach my trachea and bronchus & $87.5(50.0-100.0)$ & $30.0(0.0-50.0)$ & $<0.001^{*}$ \\
\hline I feel the inhaled drug irritate me & $55.0(50.0-100.0)$ & $12.5(0.0-50.0)$ & $0.001^{*}$ \\
\hline \multicolumn{4}{|l|}{ Overall satisfaction } \\
\hline Overall, I am satisfied with the inhaler & $60.0(50.0-80.0)$ & $50.0(50.0-80.0)$ & 0.175 \\
\hline
\end{tabular}

Values are presented as median (interquartile range).

${ }^{*} \mathrm{p}<0.05$, in comparing variables between the two pMDIs.

pMDI: pressurized metered-dose inhaler; PP: per protocol; FORM: formoterol; BDP: beclomethasone dipropionate; BUD: budesonide.

tion did not differ between the two pMDIs. At the end of the study, 11 (45.8\%), 12 (50.0\%), and one (4.2\%) chose FORM/ BDP, FORM/BUD, and another ICS/LABA (fluticasone/ vilanterol), respectively, as inhalers for use (Supplementary Figure 1A). However, based on the assumption that FORM/ BDP had a dose counter, 15 (62.5\%), eight (33.3\%), and one (4.2\%) chose FORM/BDP, FORM/BUD, and another ICS/ LABA (fluticasone/vilanterol), respectively, as inhalers that they would be willing to use (Supplementary Figure 1B).

\section{Discussion}

In this study, two lung function parameters including $\mathrm{FEV}_{1} / \mathrm{FVC}$ and $\mathrm{FEF}_{25-75}$ increased in the FORM/BDP group more than in the FORM/BUD group 8 weeks after treatment. $\mathrm{FEF}_{25-75}$ and $\mathrm{FEV}_{1} / \mathrm{FVC}$ are indicators of airflow limitation ${ }^{23,24}$. In particular, $\mathrm{FEF}_{25-75}$ is generally considered an approximate measure of the distal airway caliber, and thus its reduction represents minor airway obstruction caused by asthma inflammation $^{25,26}$. Our results suggest that FORM/BDP, an ICS/ LABA with extra-fine particles, may be intrinsically more effective in terms of lung function because it reaches the distal airways, consequently relieving airway constriction. Inhaled drugs with small particles are more evenly deposited in the lung after inhalation, which may suggest that asthma can be more effectively controlled using these medications ${ }^{27}$. Moreover, inhaled drugs with extra-fine particles are more effectively distributed, in particular in the peripheral airway, which can contribute to more uniform therapeutic effects on the patient's lung ${ }^{14}$. In a clinical study, inhaled drugs with extrafine particles resulted in better asthma treatment outcomes in elderly asthmatics compared with the same dose of drugs with non-extra-fine particles ${ }^{16}$. Furthermore, ICS/LABA with extra-fine particles resulted in less frequent AE than other ICS/ LABAs with non-extra-fine particles ${ }^{17}$. However, there were no differences in other treatment outcomes, such as ACT, ACQ, QLQAKA, asthma control, $\mathrm{AE}, \mathrm{FeNO}, \mathrm{FVC}$, or $\mathrm{FEV}_{1}$, during our 
study. The relatively short study period and the small number of subjects in this study may have hampered sufficient evaluation of the potential therapeutic benefits of extra-fine formulations. Further clinical trials are required to elucidate the roles of inhaled drugs with extra-fine particles in asthma.

In our study, a feeling of dry throat, cough, voice difficulty, and hoarseness were common adverse events with frequencies ranging from $20.8 \%$ to $37.5 \%$, which is consistent with previous reports ${ }^{28}$. These adverse effects did not differ between the FORM/BDP and FORM/BUD groups. Most of them could have been associated with upper airway irritation regardless of the size of the inhaled drugs. Meanwhile, other studies comparing BDP and BUD have reported that BDP is associated with greater side effects, such as cough, than $\mathrm{BUD}^{29}$.

A cross-sectional survey reported that one-third of physicians had no preference for inhaler type across asthma, chronic obstructive pulmonary disease (COPD), and asthmaCOPD overlap, and simplicity of use and ease of use were the most important inhaler attributes from the patients' perspective $^{30}$. Ease of use of the inhaler can affect the patient's treatment outcomes. In a qualitative study of new DPIs and other devices, participants with asthma and COPD had high levels of satisfaction with new DPIs because of ease of use, simplicity of operation, and the design of the mouthpiece, which may have positive implications for adherence to therapy ${ }^{31}$. In another study, a breath-actuated and easy-to-use DPI showed fewer critical errors that impeded delivery of sufficient doses of drugs and higher satisfaction leading to improved adherence and, consequently, more effective therapy ${ }^{32}$. Patients with asthma or COPD tend to switch to an inhaler that can be used accurately and easily during episodes of breathing difficulties and is easy to prepare and track the remaining number of doses ${ }^{33}$. In our study, there were no differences in preference for the two pMDIs in terms of ease, convenience, design, size, or grip. Meanwhile, assuming that FORM/BDP had a dose counter, subjects preferred FORM/BDP as an inhaler they were willing to use. Devices with dose counters can be more attractive choices for patients. Subjects in our study responded that the taste of FORM/BDP was stronger than that of FORM/BUD, but there were no differences in preference between the two pMDIs. In a previous study comparing two pMDIs and one DPI, there were no differences in preference with regard to smell or taste, although subjects felt there was a significant difference among the three inhalers ${ }^{11}$.

A previous study using gamma scintigraphy reported that a higher flume velocity of an inhaler can increase oropharyngeal deposition ${ }^{34}$. For this reason, pMDIs were developed to have lower flume velocities. Meanwhile, slow inhalation using a pMDI allows inhaled drugs to be deposited more diffusely and evenly into the lungs ${ }^{35}$. However, subjects in our study responded that FORM/BDP, which was thought to have a higher flume velocity, was more useful than FORM/BUD, and felt that FORM/BDP reached the trachea and bronchus more effectively than FORM/BUD, although it irritated them. Adequate inhaler-handling information and education should be provided to patients, which may lead to better compliance and treatment outcomes.

There are some limitations to this study. First, the study population was small, which limited the statistical power. In addition, loss to follow-up in randomized controlled trials can bias results. Further studies with a larger sample size and reduced loss to follow-up are required to compare asthma treatment outcomes and patient preferences for inhaler devices. Second, the 8-week study period may have been insufficient to evaluate preferences for devices and treatment outcomes. Studies with longer follow-up periods are required to confirm our results. Third, only a few validated methods are available to assess patient satisfaction and preferences ${ }^{22}$. Despite these limitations, a strength of this study is that it compared two pMDIs head-to-head in the form of a double-blind, doubledummy randomized parallel clinical trial. The overall treatment outcomes including quality of life, the primary endpoint in this study, did not differ between the two groups. However FORM/BDP improved $\mathrm{FEF}_{25-75}$ and $\mathrm{FEV}_{1} / \mathrm{FVC}$ more than FORM/BUD after 8 weeks of treatment, which suggests that inhaled drugs with extra-fine particles are better therapeutically against inflammation and bronchoconstriction of small airways than those with non-extra-fine particles.

Asthma control using pMDIs with extra-fine particles may relieve smaller airway obstruction more than that those with non-extra-fine particles despite no significant differences in overall treatment outcomes. In addition, asthma patients may prefer specific pMDIs for reasons that may not be consistent with health care providers' expectations, such as high flume velocity.

\section{Authors' Contributions}

Conceptualization: Kang SY, Lee SM, Kim TB, Lee SP. Methodology: Kang SY, Lee SM, Kim TB, Lee SP. Formal analysis: Nam TH, Kang SY, Lee SM, Kim TB, Lee SP. Data curation: Kang SY, Lee SM. Writing - original draft preparation: Nam TH, Kang SY, Lee SM. Writing - review and editing: Nam TH, Kang SY, Lee SM, Kim TB, Lee SP. Approval of final manuscript: all authors.

\section{Conflicts of Interest}

No potential conflict of interest relevant to this article was reported. 


\section{Acknowledgments}

We are especially grateful to Hyun Joo Im, a clinical research coordinator for her devotion to our study. Placebos of FORM/ BDP and FORM/BUD were provided without cost by Kolon pharma (Gwacheon, Republic of Korea) and AstraZeneca Korea (Seoul, Republic of Korea).

\section{Funding}

This research was supported by a grant of the Korea Health Technology R\&D Project through the Korea Health Industry Development Institute (KHIDI), funded by the Ministry of Health \& Welfare, Republic of Korea (grant number: HI19C0481, HC20C0076).

\section{Supplementary Material}

Supplementary material can be found in the journal homepage (http://www.e-trd.org).

Supplementary Table S1. Adverse events in PP population $(\mathrm{n}=24)$.

Supplementary Figure S1. Inhalers selected by subjects for prescription at the end of the study assuming that FORM/BDP did (A) or did not (B) have a dose counter. *The other inhaler was fluticasone furoate/vilanterol. FORM: formoterol fumarate dihydrate; BDP: beclomethasone dipropionate; BUD: budesonide.

\section{References}

1. GBD Chronic Respiratory Disease Collaborators. Prevalence and attributable health burden of chronic respiratory diseases, 1990-2017: a systematic analysis for the Global Burden of Disease Study 2017. Lancet Respir Med 2020;8:585-96.

2. National Institute of Health, National Heart Lung and Blood Institute. A Global Initiative for Asthma: global strategy for asthma management and prevention. NHLBI/WHO workshop report no. 02-3659 January 1995, updated 2020. Bethesda: National Heart Lung and Blood Institute; 2020.

3. Rohatagi S, Appajosyula S, Derendorf H, Szefler S, Nave R, Zech K, et al. Risk-benefit value of inhaled glucocorticoids: a pharmacokinetic/pharmacodynamic perspective. J Clin Pharmacol 2004;44:37-47.

4. Lavorini F, Corrigan CJ, Barnes PJ, Dekhuijzen PR, Levy ML, Pedersen S, et al. Retail sales of inhalation devices in European countries: so much for a global policy. Respir Med 2011; 105:1099-103.

5. Yun Kirby S, Zhu CQ, Kerwin EM, Stanford RH, Georges G. A preference study of two placebo dry powder inhalers in adults with COPD: ELLIPTA(R) Dry Powder Inhaler (DPI) versus DISKUS(R) DPI. COPD 2016;13:167-75.

6. Sandler N, Hollander J, Langstrom D, Santtila P, Saukkonen A, Torvinen S. Evaluation of inhaler handling-errors, inhaler perception and preference with Spiromax, Easyhaler and Turbuhaler devices among healthy Finnish volunteers: a single site, single visit crossover study (Finhaler). BMJ Open Respir Res 2016;3:e000119.

7. Giner J, Villarnovo Cerrillo M, Aboin Sierra J, Casas Herrero L, Patino O, Plaza V. Assessment of inhalation errors, training time and patient preference for DuoResp(R) Spiromax(R) and Symbicort(R) Turbuhaler(R) in patients with asthma and COPD. Eur Clin Respir J 2020;8:1833411.

8. von Schantz S, Katajavuori N, Antikainen O, Juppo A. Evaluation of dry powder inhalers with a focus on ease of use and user preference in inhaler-naive individuals. Int J Pharm 2016;509:50-8.

9. Busse WW, Brazinsky S, Jacobson K, Stricker W, Schmitt K, Vanden Burgt J, et al. Efficacy response of inhaled beclomethasone dipropionate in asthma is proportional to dose and is improved by formulation with a new propellant. J Allergy Clin Immunol 1999;104:1215-22.

10. Tonnel AB, Bons J, Legendre M, Prud'Homme A, Bugnas B, Evano-Celli I, et al. Clinical efficacy and safety of fluticasone propionate 250 microg twice daily administered via a HFA 134a pressurized metered dose inhaler to patients with mild to moderate asthma. French study group. Respir Med 2000;94 Suppl B:S29-34.

11. Bunnag C, Fuangtong R, Pothirat C, Punyaratabandhu P. A comparative study of patients' preferences and sensory perceptions of three forms of inhalers among Thai asthma and COPD patients. Asian Pac J Allergy Immunol 2007;25:99-109.

12. Papi A, Paggiaro PL, Nicolini G, Vignola AM, Fabbri LM; Inhaled Combination Asthma Treatment versus SYmbicort (ICAT SY) Study Group. Beclomethasone/formoterol versus budesonide/formoterol combination therapy in asthma. Eur Respir J 2007;29:682-9.

13. Papi A, Paggiaro P, Nicolini G, Vignola AM, Fabbri LM; ICAT SE Study Group. Beclomethasone/formoterol vs fluticasone/ salmeterol inhaled combination in moderate to severe asthma. Allergy 2007;62:1182-8.

14. Nicolini G, Scichilone N, Bizzi A, Papi A, Fabbri LM. Beclomethasone/formoterol fixed combination for the management of asthma: patient considerations. Ther Clin Risk Manag 2008;4:855-64.

15. Leach C, Colice GL, Luskin A. Particle size of inhaled corticosteroids: does it matter? J Allergy Clin Immunol 2009;124(6 Suppl):S88-93.

16. Benfante A, Basile M, Battaglia S, Spatafora M, Scichilone N. Use of ICS/LABA (extra-fine and non-extra-fine) in elderly asthmatics. Ther Clin Risk Manag 2016;12:1553-62.

17. Papi A, Mansur AH, Pertseva T, Kaiser K, McIver T, Grothe B, et al. Long-term fluticasone propionate/formoterol fumarate 
combination therapy is associated with a low incidence of severe asthma exacerbations. J Aerosol Med Pulm Drug Deliv 2016;29:346-61.

18. Kwon HS, Lee SH, Yang MS, Lee SM, Kim SH, Kim DI, et al. Correlation between the Korean version of Asthma Control Test and health-related quality of life in adult asthmatics. J Korean Med Sci 2008;23:621-7.

19. Kim MK, Park HS, Park CS, Min SJ, Albers FC, Yancey SW, et al. Efficacy and safety of mepolizumab in Korean patients with severe eosinophilic asthma from the DREAM and MENSA studies. Korean J Intern Med 2021;36:362-70.

20. Park JW, Cho YS, Lee SY, Nahm DH, Kim YK, Kim DK, et al. Multi-center study for the utilization of quality of life questionnaire for adult Korean asthmatics (QLQAKA). J Asthma Allergy Clin Immunol 2000;20:467-80.

21. Lee SM, Chang YS, Kim CW, Kim TB, Kim SH, Kwon YE, et al. Skills in handling turbuhaler, diskus, and pressurized metered-dose inhaler in Korean asthmatic patients. Allergy Asthma Immunol Res 2011;3:46-52.

22. Kozma CM, Slaton TL, Monz BU, Hodder R, Reese PR. Development and validation of a patient satisfaction and preference questionnaire for inhalation devices. Treat Respir Med 2005;4:41-52.

23. Miller MR, Hankinson J, Brusasco V, Burgos F, Casaburi R, Coates A, et al. Standardisation of spirometry. Eur Respir J 2005;26:319-38.

24. Macklem PT. The physiology of small airways. Am J Respir Crit Care Med 1998;157(5 Pt 2):S181-3.

25. van den Berge M, Ten Hacken NH, Cohen J, Douma WR, Postma DS. Small airway disease in asthma and COPD: clinical implications. Chest 2011;139:412-23.

26. Lebecque P, Kiakulanda P, Coates AL. Spirometry in the asthmatic child: is FEF25-75 a more sensitive test than $\mathrm{FEV}_{1} /$ FVC? Pediatr Pulmonol 1993;16:19-22.

27. Hauber H, Taha R, Bergeron C, Migounov V, Hamid Q, Olivenstein R. Effects of hydrofluoroalkane and dry powder- formulated corticosteroids on sputum inflammatory markers in asthmatic patients. Can Respir J 2006;13:73-8.

28. Foster JM, Aucott L, van der Werf RH, van der Meijden MJ, Schraa G, Postma DS, et al. Higher patient perceived side effects related to higher daily doses of inhaled corticosteroids in the community: a cross-sectional analysis. Respir Med 2006;100:1318-36.

29. Worth H, Muir JF, Pieters WR. Comparison of hydrofluoroalkane-beclomethasone dipropionate Autohaler with budesonide Turbuhaler in asthma control. Respiration 2001; 68:517-26.

30. Ding B, Small M, Scheffel G, Holmgren U. Maintenance inhaler preference, attribute importance, and satisfaction in prescribing physicians and patients with asthma, COPD, or asthma-COPD overlap syndrome consulting for routine care. Int J Chron Obstruct Pulmon Dis 2018;13:927-36.

31. Svedsater H, Dale P, Garrill K, Walker R, Woepse MW. Qualitative assessment of attributes and ease of use of the ELLIPTA dry powder inhaler for delivery of maintenance therapy for asthma and COPD. BMC Pulm Med 2013;13:72.

32. Magnussen H, Fyrnys B, Greguletz R. Genuair $((\mathrm{R})) /$ Pressair ((R)) inhaler in COPD: the patient perspective. COPD 2019;16:196-205.

33. Hawken N, Torvinen S, Neine ME, Amri I, Toumi M, Aballea $S$, et al. Patient preferences for dry powder inhaler attributes in asthma and chronic obstructive pulmonary disease in France: a discrete choice experiment. BMC Pulm Med 2017; 17:99.

34. Newman S, Pitcairn G, Steed K, Harrison A, Nagel J. Deposition of fenoterol from pressurized metered dose inhalers containing hydrofluoroalkanes. J Allergy Clin Immunol 1999;104: S253-7.

35. Usmani OS, Biddiscombe MF, Barnes PJ. Regional lung deposition and bronchodilator response as a function of beta2-agonist particle size. Am J Respir Crit Care Med 2005;172:1497504. 